\title{
Helioclimatology of the Alps and the Tibetan Plateau
}

\author{
Bakhram Nurtaev \\ Institute of Helioclimatology, Frechen, Germany
}

Email address:

nurtaev@gmx.net

\section{To cite this article:}

Bakhram Nurtaev. Helioclimatology of the Alps and the Tibetan Plateau. Earth Sciences. Vol. 5, No. 2, 2016, pp. 19-25.

doi: $10.11648 /$ j.earth.20160502.11

Received: February 1, 2016; Accepted: March 21, 2016; Published: April 20, 2016

\begin{abstract}
There is broad agreement that the energy from the Sun is very important to the Earth. Global atmospheric circulation is also strongly affected by the amount of solar radiation received at Earth. That amount changes based on the Earth's albedo, that is how much radiation is reflected back from the Earth's surface and clouds. The amount of radiation given off by the Sun is changing with solar activity like sunspots and total solar irradiance. A reconstruction of total solar irradiance since 1610 to the present estimated by various authors an increase in the total solar irradiance since the Maunder Minimum of about $1.3 \mathrm{~W} / \mathrm{m}^{2}$. This is a huge amount of energy, taking into account the Earth's total land mass - $510.072 \mathrm{million} \mathrm{sq} \mathrm{kms}$. During this period, an increase in temperature in the Northern Hemisphere was observed. This paper examines air temperature variation and an associated phenomenon of its relationships to solar activity indices. The purpose of this study is to identify contribution of the Sun on climate variability in two mountainous regions of the Earth: the Alps and the Tibetan Plateau. Methodology applied in this study is based on calibration of the smoothed International Sunspot Number (SSN) and air temperature for the same solar cycles over a period of many years.
\end{abstract}

Keywords: Climate Variability, Solar Activity, Sunspots, Air Temperature

\section{Introduction}

The Earth's climate has changed throughout all geological history of the Earth. The movement of the Earth's plates and orbital forcing (Milankovitch's theory) are believed to explain climate changes that occur over tens or hundreds of millions of years. Observations show climate behavior is much more intense than the calculated variations. The major driving force of the atmosphere circulation is solar heating which provides the continuous movement of air [3]. The sun radiates uniformly in all directions, mainly visible light and infrared radiation. The Earth moves around the Sun and receives a different amount of sunlight and heat, at first due to night and day, at second due to orbit of the planet. This movement creates prevailing winds on the Earth (Westerlies in the Northern Hemisphere and Easterlies in Southern Hemisphere) and due to Coriolis force the Golf stream and other warm currents.

The sun provides $99.97 \%$ of the earth's energy budget. The current world energy consumption is equivalent to $0.007 \%$ of the incident solar energy [9]. Sunspot number time series can be conceived as indicators of climate trends.
Extraterrestrial solar-irradiance variations are associated with variations in regional climatology by means of global atmospheric circulation. In order to reliably evaluate the Sun's role in climate variability, longer time series are needed [8]. For example, solar observations over the last century show a long term increase trend of solar activity. During this period also was observed an increase in temperature in the Northern Hemisphere. The averaged sunspot number risen about $40 \%$ and temperature change on $-4-10 \%$.

Instrumental temperature records period accumulated a huge database of air temperature. This database processing gives us actually uncertainty of future climate scenarios as many years ago. Application of helioclimatology can significantly help to determine the direction of future trend in spite of a short period of observations (in comparison with Earth's age). Changes in solar activity affect the entire Earth.

The physical basis of the influence of solar activity on the climate is evident. The sun's heat and light energy are warms the land surface and oceans and radiates heat back into the air above. Increases in the number of sunspots and magnetic 
solar activity lead to an increase in solar energy. Solar heating on average is largest near the equator and smallest at the poles. The atmospheric circulation transports energy polewards, thus reducing the resulting equator-to-pole temperature gradient.

\section{Materials and Methods}

The F10, $7 \mathrm{~cm}$ index is a standard characteristic of solar activity using in research concerning the solar influence on Earth's climate. Comparison of F10, $7 \mathrm{~cm}$ index with Wolf's Numbers detected close correlation between these both parameters $r=0,99$ over the period 1947-2008, Figure 1. The

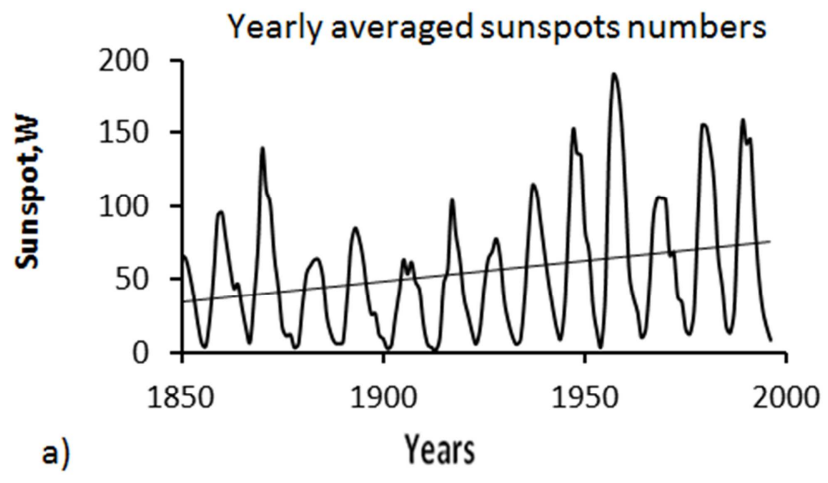

solar radio flux at F10.7 cm record extends back to 1947.

The sunspot number $-\mathrm{W}$ is the direct record of the evolution of the solar cycle over multiple centuries and is the longest scientific experiment since 1750 still ongoing. Taking into account strong correlation between sunspots and F10, 7 $\mathrm{cm}$ index, we examined empirical inverse model relationships between long - term mean air temperature and sunspots for one solar cycle on basis of smoothed averaged sunspots number and air temperature proposed from Nurtaev [6]. Many solar phenomena change periodically over an average interval of about 11 years [11]. This solar cycle affects solar irradiation and influences space weather, terrestrial weather and climate.

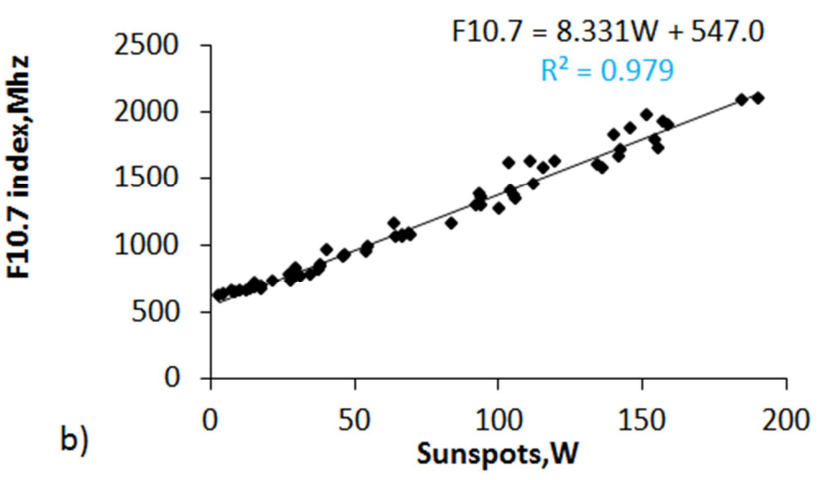

Figure 1. Sunspot trend (a) and comparison of Yearly Sunspot Number and 10.7 cm Flux (b) over the period 1947-2008.

Data used in this study are from NASA Surface Temperature Data [7], HISTALP - Historical Instrumental Climatological Surface Time Series of the Greater Alpine Region [2] and Solar Influences Data Analysis Center (SIDC) -original international Sunspot number data were used in this study (2013). The sunspot number time series is the longest record made in science.

\section{Results and Discussions}

\subsection{The Alps}

The Alps are a crescent shaped geographic feature of central Europe that ranges in $800 \mathrm{~km}$ from east to west and is $200 \mathrm{~km}$ in width. The mean height of the mountain peaks is $2.5 \mathrm{kms}$.

The Alps mountain range creates a natural barrier for direct atmosphere intrusion from equatorial area into northern Europe. The location of the Alps, as well as the great variations in their elevations and exposure, give rise to extreme differences in climate. Because of their central location in Europe, the Alps are affected by four main climatic influences: from the west flows the relatively mild, moist air of the Atlantic; cool or cold polar air descends from northern Europe; continental air masses, cold and dry in winter and hot in summer, dominate in the east; and, to the south, warm Mediterranean air flows northward.

Over the last century, global warming has caused all Alpine glaciers to recede. In 2006, the volume of water stored as ice was still almost $10 \%$ greater than that present as liquid, but the margin is continuing to narrow. Global warming will also bring about changes in rain and snowfall patterns and an increase in the frequency of extreme meteorological events, such as floods and avalanches. The dependence of solar energy received in the different parts of mountains varies strongly. Annual mean net radiation goes from about $50 \mathrm{Wm}^{2}$ at the lowland stations to almost zero (but still positive) at high altitude stations, causing an altitude gradient of $-1.4 \mathrm{Wm}^{2} / 100 \mathrm{~m}$ [5]. This decrease is mainly caused by high reflection coefficient of glaciers and also due to longer duration of the snow cover. Temperature increase at the higher stations mostly depends on global atmospheric circulation, which has warming trend, than from direct sunshine.

The period for which reasonably reliable instrumental records of near-surface temperature exist with quasi-global coverage is generally considered to begin around 1850 . Earth's average temperature rose by $0.7^{\circ} \mathrm{C}$ over this period. Global warming is affecting the higher latitudes more than any other part of the world. Temperature rise in low latitudes reach - $+4 \%$ and $+7 \%$ in high latitudes. In case of the Alps the average surface temperatures have increased by about $1.0-1.5^{\circ} \mathrm{C}$ over the last 100 years.

Analysis of the long-term temperature records at the lowland stations in the Alpine Region detected also close interrelation with solar activity. Results show that above $80 \%$ level of statistically significant correlations exist between sunspots and air temperature. Calculation period for all calculated stations extends over the period 1855-1996. 


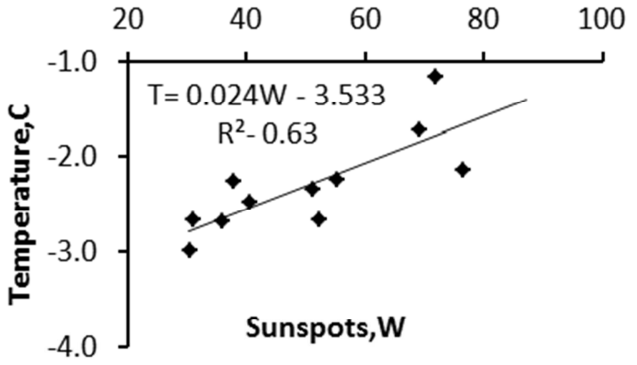

a) Säntis, 1867-1996

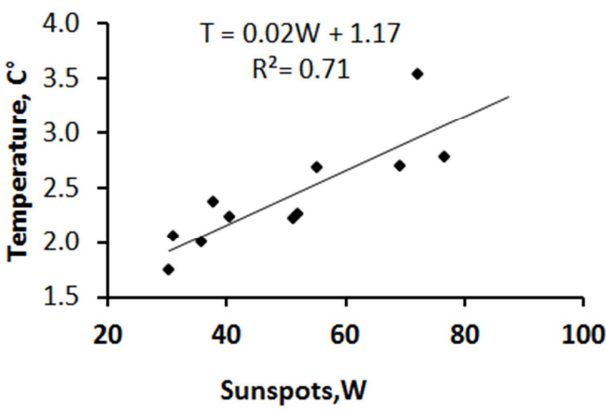

c) Davos, $1867-1996$

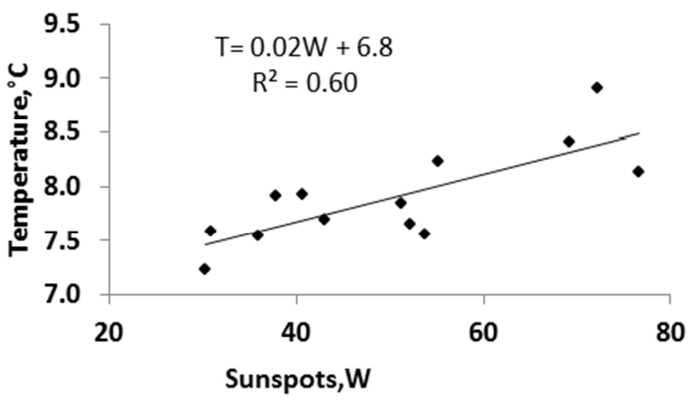

e) Salzburg,1843-2008

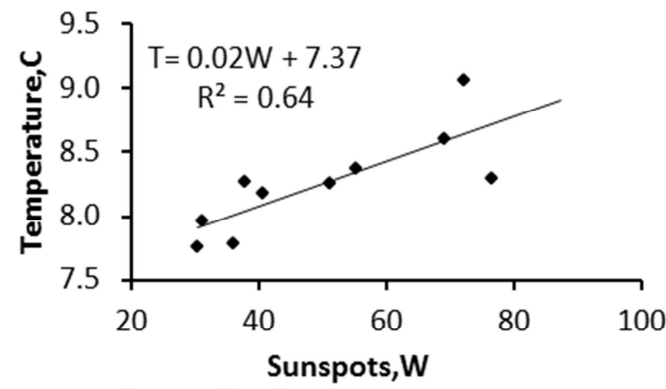

g) Innsbruk,1878-1996

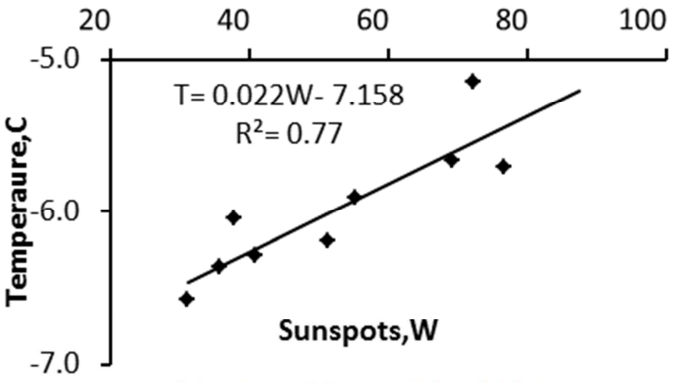

b) Sonnblick, $1890-1996$
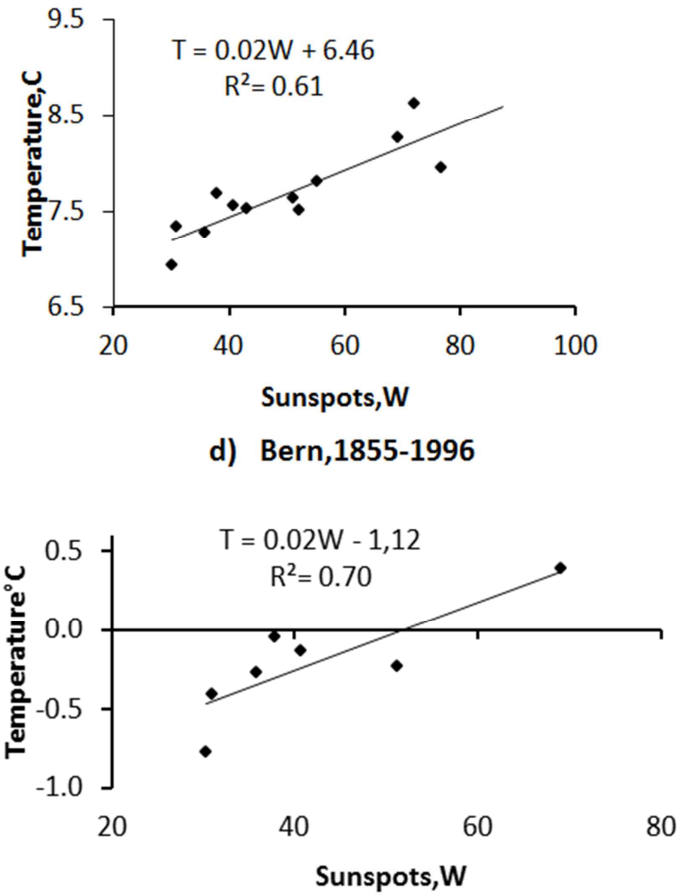

f) St.Gotthards,1878-1954

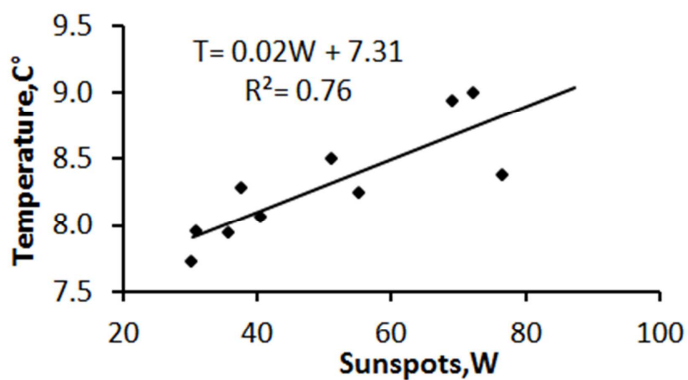

h) Zurich,1878-1996

Figure 2. Relationships of air temperature of different weather stations at the Alps from solar activity over a period of many years.

Empirical relationships between temperatures in the studied area in dependence on solar activity in weather stations presented below:

Karlsruhe, $\mathrm{T}=0.03 \mathrm{~W}+8.4 ; \mathrm{R}^{2}=0.69$

Lugano, $\mathrm{T}=0.02 \mathrm{~W}+10.7 ; \mathrm{R}^{2}=0.81$

Munich, $\mathrm{T}=0.02 \mathrm{~W}+6.6 ; \mathrm{R}^{2}=0.80$

Salzburg, $\mathrm{T}=0.02 \mathrm{~W}+6.8 ; \mathrm{R}^{2}=0.60$

Stuttgart, $\mathrm{T}=0.03 \mathrm{~W}+7.7 ; \mathrm{R}^{2}=0.66$
Zürich, $\mathrm{T}=0.02 \mathrm{~W}+7.1 ; \mathrm{R}^{2}=0.76$

Bratislava $\mathrm{T}=0.02 \mathrm{~W}+7.7 ; \mathrm{R}^{2}=0.79$

Budapest $\mathrm{T}=0.02 \mathrm{~W}+8.9 ; \mathrm{R}^{2}=0.77$

where- $\mathrm{T}$ is temperature of air in ${ }^{\circ} \mathrm{C}, \mathrm{W}$ is the number of sunspots, $\mathrm{R}^{2}$ is the coefficient of determination.

Temperature rise due to solar radiation is actually conventional. This means that more sunspots deliver more energy to the atmosphere, so that global temperatures rise. 
Precipitation trends in the same stations in dependence from solar activity are not so homogeneous, Figure 3.

Precipitation in simplified form can be conceived as a process of evaporation of surface water under the influence of sunlight and fall of condensed water back to the earth surface. The sun regularly bathes the Earth's equator with enormous amount of solar energy. This energy evaporates water, causes atmospheric convection and is transported polewards by winds. The hydrological cycle is a closed system, because there are no external inputs or outputs of water to or from the system. The same water has been continually circulating since the beginnings of life on Earth. Amount of water circulated in
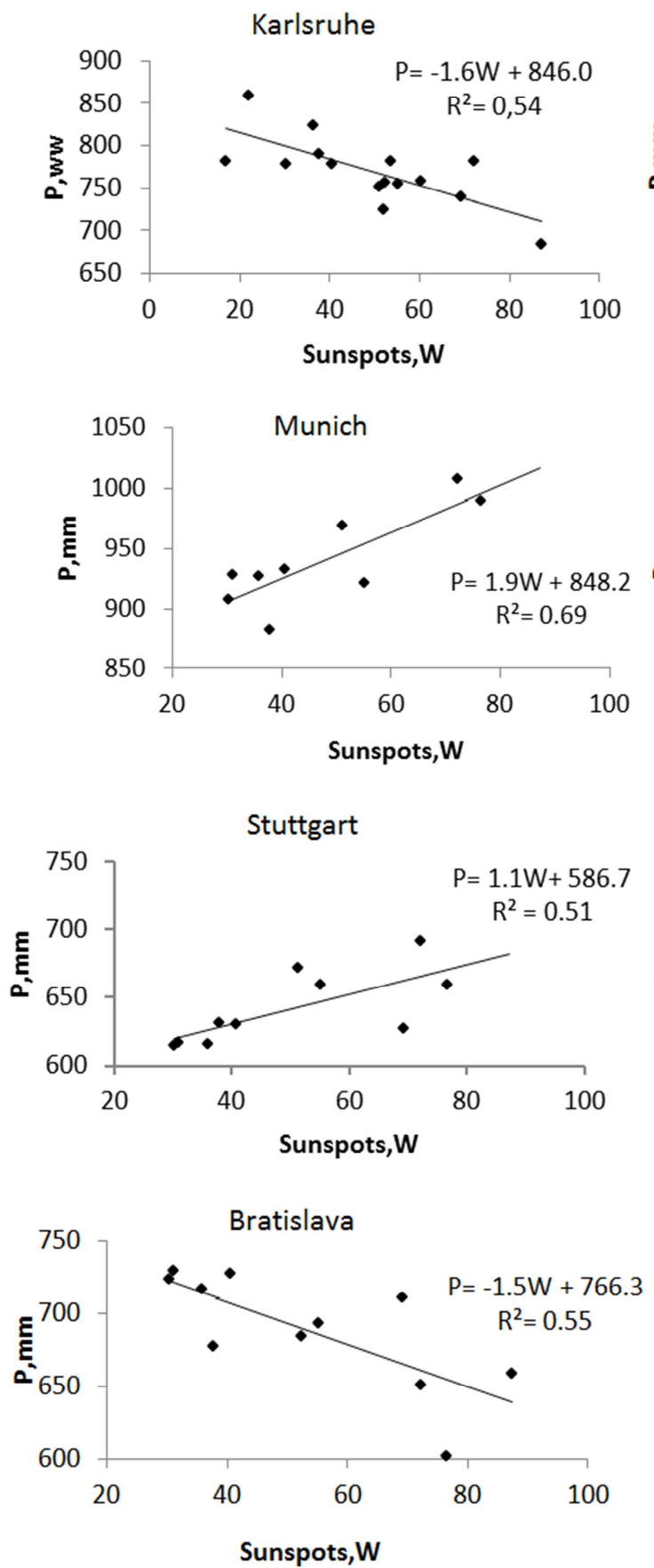

atmosphere and hydrosphere depends eventually on capacity and a finite extension of the atmosphere due to warming as well as from the Earth gravitational force for the vapour water molecule in atmosphere.

Increasing temperatures tend to increase evaporation which leads to intensification of hydrological cycle. In this way the orographic effect is a change in atmospheric conditions caused by a change in elevation, primarily due to mountains. The mountain ranges intercept evaporated water mass transfer. The climate on the leeward side of a mountain differs from that on the windward side mostly in the amount of rainfall.
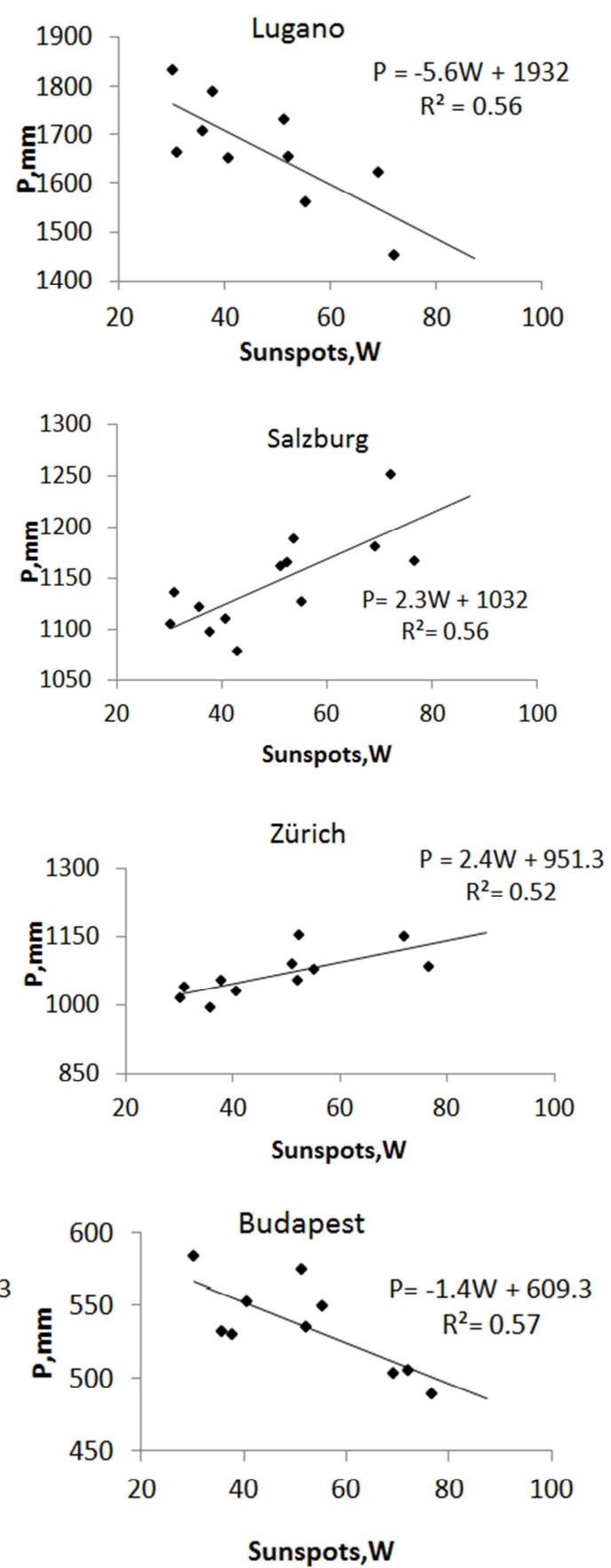

Figure 3. Empirical relationships between averaged precipitation and solar activity in the Greater Alpine Region over the period 1878-1996. where Pprecipitation in $\mathrm{mm}, W$-number of the sunspots, $R^{2}$-coefficient of determination. 


\subsection{The Tibetan Plateau}

Tibet climate depends on general geographical location of China. The climate of China is dominated by the great seasonal wind reversal called the Asiatic monsoon. From October until April winds tend to blow out from China and the heart of Asia under the influence of the great highpressure system which develops in Siberia and central Asia at this time.

From May until September or October, as the continent of Asia heats up, this area becomes one of low atmospheric pressure and winds are drawn into much of China, both from the Indian Ocean and the Pacific.

These warm, moist winds bring most of the annual rainfall to China at this time. The Tibetan, Xinjiang Uygur, and Inner Mongolian autonomous regions, furthest removed from the influence of the sea, receive much less rain.

North China, including Manchuria, has extremely cold winters of almost Siberian severity, while Inner Mongolia and Xinjiang Uygur share in this winter cold. Tibet, being a great upland plateau rimmed by some of the highest mountains in the world, has cool summers and very cold winters.

Tibet, the world's largest and highest plateau, is widely known as the Third Pole because its ice fields contain the largest reserve of fresh water outside of the Arctic and Antarctic [4]. The Tibetan furthest removed from the influence of the sea, receives much less rain. Tibet, being a great upland plateau rimmed by some of the highest mountains in the world, has cool summers and very cold winters. This is a region of high plateaux and encircling mountains, situated in southwestern China. Its southern boundary includes the highest peaks of the Himalayas, such as Everest. Most of the region is above 3,700 $\mathrm{m}$ and some extensive areas rise above 4,900 $\mathrm{m}$.

Winters are severe with frequent light snow and hard frost. Considering the altitude, summer temperatures are surprisingly warm in the daytime, but there is a very sharp drop in temperature at night. Most of the precipitation is rain during the summer, when moist air is drawn into the region by the Asian monsoon winds.

In the west and north of the region some winter precipitation falls as snow; but the permanent snowline is surprisingly high at about $6,600 \mathrm{~m}$. Apart from the low temperatures, strong winds, which accentuate wind chill, are the worst feature of the climate. For much of the year the air is very clear and sunshine is abundant. 3500 by $1500 \mathrm{~km}$ large plateau with its remarkably uniform flatness is beaten increasingly by solar radiation in large amounts. The Himalayan barrier causes profound perturbations in the circulation of winds including moisture-laden air.

Without the Himalayan ranges, which cause precipitation of moisture from the passing clouds, much of the Indian subcontinent would be a dry desolate land. The high ranges that prevent the south-west monsoon clouds to go north are also responsible for the drier conditions in Tibet in the north and western Rajasthan in the south. The snow-covered ranges have exercised a moderating influence on the temperature and humidity in the Indian subcontinent. The Himalaya stops the Siberian wintry cold winds

Because this highland is at subtropical latitude, with 4 to 5 times the insolation of high-latitude areas, what would be Earth's strongest heating surface has turned into a cooling surface. The east west ranges of the Himalayas have southern slopes which will receive comparatively more radiation thereby hastening the melting process. On the northern slopes the snow will melt later. The mountain barrier must have disrupted west-to-east flow of winds and caused northward displacement of high pressure centre that commonly lies near the $30^{\circ}-35^{\circ}$ latitudes, so that the low-pressure centre moved over northern India in summer [11].

In accordance with long term study of Qin Dahe et al [1], snow cover in the past 47 years between 1951 and 1997 has the positive trend of the western China is consistent with increasing snowfall, but is in contradiction to regional warming. The authors found that snow seasons over the Tibetan Plateau normally begin in mid-September. The winter, spring (March-April-May), and autumn (SeptemberOctober-November) are represented by $45.2 \%, 28.0 \%$, and $21.2 \%$ of the annual snow storage, respectively. The annual cumulative daily snow depth increased by $2.3 \% \mathrm{yr}^{-1}$ over the Tibetan Plateau during the period between 1957 and 1998. The authors conclude, the increasing trend of western China snow cover is in good agreement with the snowfall positive trend, but is in contradiction to the regional warming.

Most meteorological stations on the Tibetan Plateau were not established until the early 1950s, with the exception of a few observational records that were collected before the 1930s. Therefore, because for detecting of the long term trend in temperature change as rule it is necessary more than 50 years observations, we calculated stations located in the peripherals part of the Tibetan Plateau. The time period considered is mainly from 1933 to 2008.In all weather stations were observed air temperature decrease over the period 1933 to 1976 about $1.0^{\circ} \mathrm{C}$ and then increase of temperature on $1.0^{\circ} \mathrm{C}$ up to prior state over the period 1976 2008. Analysis of the long-term temperature records at the plateau stations in the detected close interrelation with solar activity. Results show that above $80 \%$ level of statistically significant correlations exist between sunspots and air temperature. Calculation period for all calculated stations extends over the period 1933-2008. The calculations show steady negative relationships trends of surface temperature in dependence from increased sunspots, Figure 4.

This contradiction to the global warming can be explained by high location and glaciers albedo of the Tibetan Plateau and Himalayan barrier for monsoon winds.

Because much of the land surface and oceans are dark in color, they have a low albedo. They absorb a large amount of the solar energy that gets to them, reflecting only a small fraction of it. Forests have low albedo, near 0.15. Snow and ice, on the other hand, are very light in color. They have very 
high albedo, as high as 0.8 or 0.9 , and reflect most of the solar energy that gets to them, absorbing very little. The Tibetan Plateau is the highest elevated land of the in the world with permafrost.
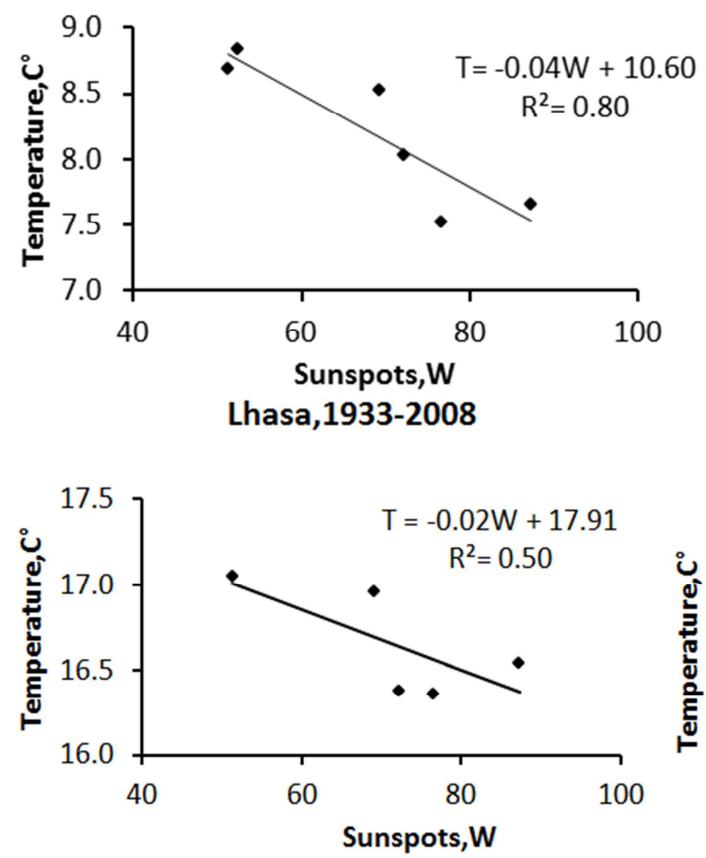

Chengdu,1933-1996
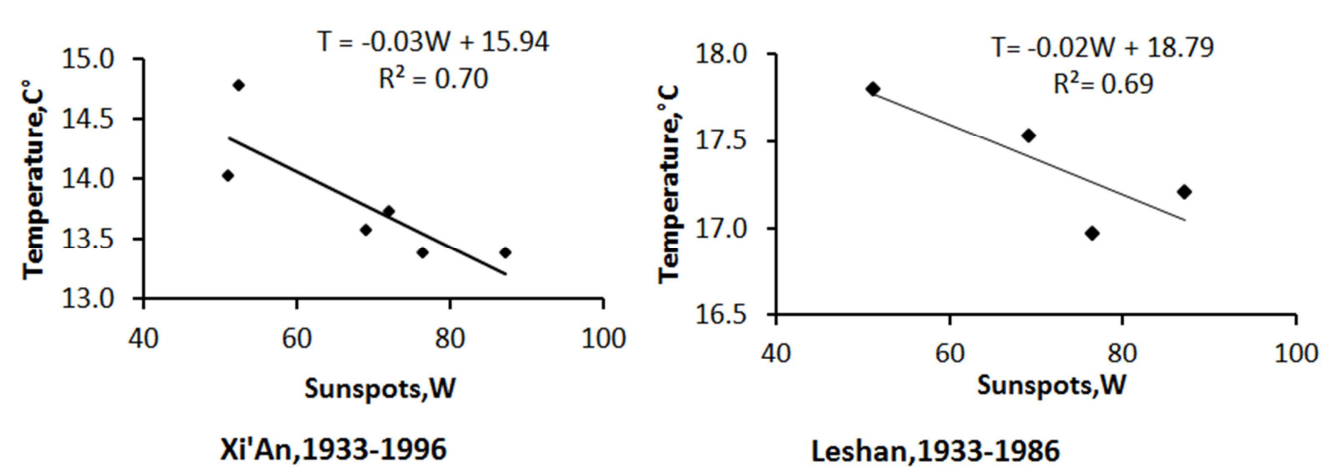

Leshan,1933-1986

The Tibetan Plateau holds approximately 45,000 glaciers covering an area of 105,000 square kilometers and comprises an area of about 2.5 million square kilometers.
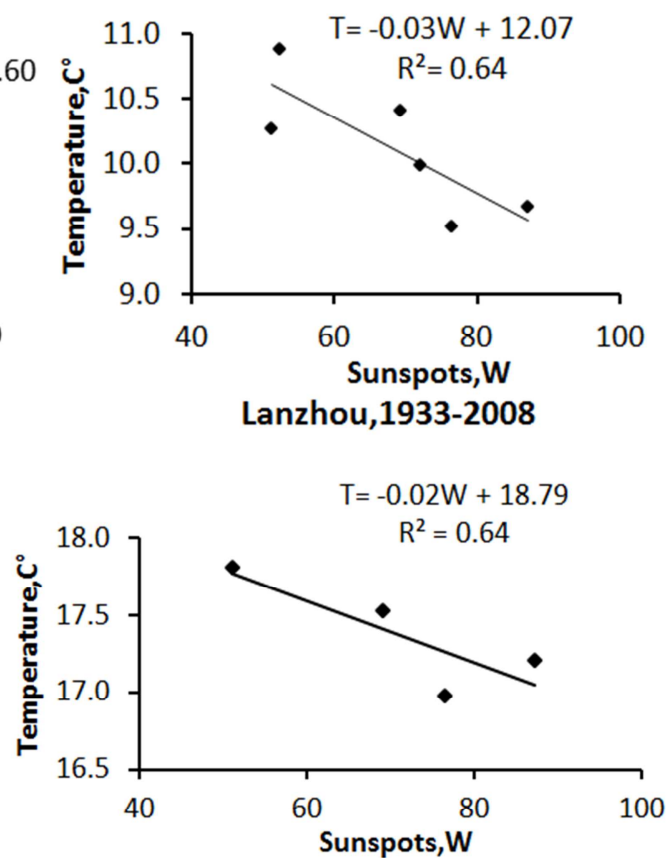

Leshan, 1933-1986

Figure 4. Relationships of air temperature of different weather stations at the Tibetan Plateau from solar activity over a period of many years.

\section{Conclusions and Recommendations}

The sun's heat and light energy are warms the land surface and oceans and radiates heat back into the air above. It is believed that increase of solar activity leads to a rise in atmospheric temperature.

More sunspots deliver more energy to the atmosphere, so that global temperatures should rise. From this point of view, the increase of air temperature in the Alps Mountains in dependence from solar activity is conventional. In the Tibetan Plateau region it is also observed a warming trend, but at the same time, our study points out a reverse phenomenon-decrease of air temperature with increase of solar activity.

In accordance with NASA forecasting the next two solar cycles will be below average in intensity. This actually will lead to a decrease of the temperature in the Alps on $1-1,5^{\circ} \mathrm{C}$ degree in the next two solar cycles. At the Tibetan Plateau we expecting temperature rise.

Temperature histories from paleoclimate data show that in future climate, two possibilities exist: either global cooling or global warming.

It is recommended, in long term forecast scenarios of climate change to take into account solar activity variability as one of the important factor.

\section{References}

[1] Dahe Q., Shiyin L., Peiji L., (2006). Snow Cover Distribution, Variability, and Response to Climate Change in Western China. J. Climate, pp. 1820-1833.

[2] HISTALP, (2013). Historical Instrumental Climatological Surface Time Series Of The Greater Alpine Region, 2013. http://www.zamg.ac.at/histalp/index.php. 
[3] D. W. Hoyt, K. H. Schatten, (1997). "The role of the sun in climate change" Oxford University Press, Oxford UK, 279 pp.

[4] M. Kuhle, (1988). The Pleistocene Glaciation of Tibet and the Onset of Ice Ages- An Autocycle Hypothesis. Geo Journal 17 (4, Tibet and High-Asia. Results of the Sino-German Joint Expeditions I), pp 581-596.

[5] Marty, C., \& Philipona, R., (2001). Surface radiation budget and cloud forcing over the Alps.: Current Problems in Atmospheric Radiation, IRS 2000. pp. 688-691.

[6] B. Nurtaev. Influence of climate variability on large rivers runoff, (2015). Proceedings of the International Association of Hydrological Sciences, 371: 211-214.

[7] NASA, GISS Surface Temperature Analysis (GISTEMP), (2013). http://data.giss.nasa.gov/gistemp/
[8] N. A. Krivova, L. Balmaceda, S. K. Solanki (2007). Reconstruction of solar total irradiance since 1700 from the surface magnetic flux. A\&A. 467, pp. 335-346.

[9] F. W. Taylor, (2005). Elementary Climate Physics, Oxford University Press, 232pp.

[10] E. Shermatov, B Nurtayev, U. Muhamedgalieva, U. Shermatov, (2004). Analysis of water resources variability of the Caspian and the Aral Sea basins on the basis of solar activity. Journal of Marine Systems 47, pp. 137-142.

[11] K. S. Valdiya. Rising Himalaya, (1999), Advent and intensification of monsoon. Current science. Vol. 76, pp 514524. 